\title{
Larvicidal activity of the skin secretion of Rhinella marina and Rhaebo guttatus (Anura: Bufonidae) against the Brazilian malaria vector, Anopheles darlingi (Diptera: Culicidae)
}

Trindade, F.T.T. ${ }^{1}$, Lucena, I.V. ${ }^{1}$, Rodrigues, M.M.S. ${ }^{2}$, Stábeli, R.G. ${ }^{3}$, Moreira-Dill, L.S. ${ }^{3}$, Soares, A.M. ${ }^{3}$, Calderon, L.A. ${ }^{3}$, Silva, A.A.E. ${ }^{1,4^{*}}$

${ }^{1}$ Departamento de Biologia, Universidade Federal de Rondônia, Porto Velho, RO, Brasil

${ }^{2}$ Fundação Oswaldo Cruz de Rondônia, Porto Velho, RO, Brasil

${ }^{3}$ Centro de Estudos de Biomoléculas Aplicadas à Saúde, Fundação Oswaldo Cruz de Rondônia, Porto Velho, RO, Brasil

${ }^{4}$ Instituto Nacional de Epidemiologia da Amazônia Ocidental, Fundação Oswaldo Cruz de Rondônia, , Porto Velho, RO, Brasil

*Corresponding author: alealsil@unir.br

\section{ARTICLE HISTORY}

Received: 24 September 2021 Revised: 22 October 2021

Accepted: 24 October 2021

Published: 21 December 2021

\begin{abstract}
Malaria, a mosquito-borne disease, is caused by protozoa of the genus Plasmodium and constitutes a serious public health problem. Because current insecticides used to control malaria face resistance due to continuous use, new alternatives are prompted. Considering this context, and the insecticidal potential of vertebrate venoms/secretions, crude and methanolic extracts from two frog species were tested as larvicides against Anopheles darlingi. Skin secretions of Rhinella marina and Rhaebo guttatus were obtained by manual stimulation. Then, methanol was added to obtain steroidal fractions from both venoms. Mosquitos were captured in suburban areas of Porto Velho and An. darlingi females were later fed with blood and stimulated to oviposit. The larvae were fed with fish food until the $3^{\text {rd }}$ and $4^{\text {th }}$ instars. For the larvicidal assays, crude secretions and methanolic fractions of both frog species were evaluated, and larvae mortality was recorded after 48 hours. Crude extracts and steroidal fractions from both species had larvicidal effects, with an $\mathrm{LC}_{50}$ of 127.5 and $133 \mathrm{ppm}$ for the crude extract and steroidal fraction of $R$. marina, and an $\mathrm{LC}_{50}$ of 37.5 and $35.8 \mathrm{ppm}$ for the crude extract and steroidal secretion of $R$. guttatus, respectively. The present work reports for the first time the larvicidal effects of the skin secretions from bufonid species occurring in the western Amazon region. Further studies should be carried out to investigate the purified components responsible for the observed activity.
\end{abstract}

Keywords: Amazon biodiversity; Anura, Rhinella; skin secretion; bufodienolides.

\section{INTRODUCTION}

Mosquito-borne diseases, such as malaria, constitute major public health problems, particularly in tropical and subtropical regions, where they are transmitted to humans during the blood feeding of Anopheles mosquitoes.

Human malaria, an infectious disease caused by protozoans of the genus Plasmodium (i.e., Plasmodium falciparum, Plasmodium vivax, Plasmodium malariae, Plamodium ovale and Plasmodium knowlesi), remains a major public health problem worldwide. In 2019, an estimated 229 million cases of malaria occurred worldwide (WHO, 2020), with more than 153,296 cases reported in Brazil and the Amazon region accounting for more than $80 \%$ of these cases (MS, 2020). The Brazilian anopheline fauna includes 54 species, but Anopheles darlingi is widely distributed in the northern region (Sinka et al., 2012) and is reported to be the major malaria vector (Tadei \& Dutary-Thatcher, 2000).
Despite efficient treatment protocols for malariainfected patients, in recent years, insecticides remain the most important tool to control Anopheles. Despite this, the resistance of An. darlingi to insecticides has been an obstacle for malaria prevention, given that the indiscriminate and inappropriate use of these chemicals has promoted the selection of multiresistant vectors (Hemingway et al., 2016). In this scenario, the importance of biodiversity as a source of new molecules for control and treatment of tropical diseases is constantly highlighted in the literature (Calderon et al., 2009; Da Silva et al., 2014; Trindade et al., 2014).

Bioinsecticides have been investigated as effective and safe alternatives to the chemical insecticides currently used, and various bioactive compounds from plants and animals have been listed as potential bioinsecticides (Carlini \& Grosssi-de-Sá, 2002; Nicholson, 2007). Thus, the search for bioinsecticide molecules from synthetic analogs, or 
alternative sources such as plants and animals, have been investigated by research groups around the world.

For a long time, plants have been the main source of bioactive compounds, but recently, studies based on natural products have intensified and their sources have expanded. Therefore, the investigation of bioactive compounds of animal origin has become increasingly common (Calderon et al., 2009), and insecticidal activity of animal venoms, such as those from spiders (Gimenez et al., 2014) and anurans (Trindade et al., 2014), against mosquitoes has already been shown.

Frogs' skin secretions are a promising source of biotechnological products based on a wide variety of toxic or noxious substances that repel or kill some predators and pathogens (Barra \& Simmaco, 1995; Calderon et al., 2009; Calderon et al., 2011) and also display biological activity against bacteria, fungi, viruses and protozoa (Rinaldi, 2002; Calderon et al., 2011).

Rhinella marina is distributed across the eastern Andes of Peru, Brazil, Colombia and Venezuela, and is popularly known as the cane toad. Often, this species is involved in accidental poisoning of dogs when the toads are bitten, causing parotid secretion release (Stuart et al., 2008; Peterson \& Roberts, 2013).

The Rhaebo genus contains nine different species, distributed in Central and South America. Rhaebo guttatus, popularly known as smooth-sided toad or spotted toad, is richly distributed in Brazil, especially in the Amazon, in the north of the country (Frost, 2021). This is the only species capable of voluntarily releasing jets of venom from its glands when threatened (Felipe Toledo et al., 2011). These toads produce a rich blend of bufodienolides, biogenic amines and proteins, which are very effective in protecting the animal against predators and microorganisms (Toledo \& Jared, 1995; Cunha-Filho et al., 2010; Rash et al., 2011).

Most previous studies have focused on the antimicrobial, antiparasitic and anticancer properties of substances from frogs' skin secretions, but some investigations (Williams et al., 1998; Weldon et al., 2006; Williams et al., 2006) have also reported insecticidal and repellent effects of different species. Trindade et al. (2014) reported very low lethal concentrations of the skin secretions of Leptodactylus knudseni and Phyllomedusa vaillantii for adults and larvae of An. darlingi, suggesting that bioactive molecules from frog skin secretions of other anuran species might have similar activity. Therefore, this work evaluated the larvicidal activity of crude and steroidal fractions from the skin secretion of $R$. marina and $R$. guttatus against An. darlingi, an important vector of malaria in south America.

\section{MATERIAL AND METHODS}

\section{Obtaining the crude venom and steroidal fraction}

Rhinella marina and $R$. guttatus adults were collected in Porto Velho, Rondonia, Brazil. The skin secretion was obtained by manual stimulation of the parotoid glands, followed by washing of the glandular dorsal region of each individual with deionized water and collection in Becker. This solution was filtered through a "steriflip" filter, lyophilized and stored at $-86^{\circ} \mathrm{C}$.

For the fractionation, dried and lyophilized venom was placed in a $100 \mathrm{~mL}$ flask containing $50 \mathrm{~mL}$ of methanol and 10 glass pearls boiling and one magnetic bat. This solution was homogenized by stirring using a magnetic stirrer for 5 minutes. Afterwards, the flask was transferred to a heating mantle and mated to the flask to a ball type condenser ( 45 $\mathrm{cm})$. The system was kept under reflux at $75^{\circ} \mathrm{C}$ for 1 hour and then placed on the magnetic stirrer for 5 minutes. The methanolic fraction was removed using a pipette and the remaining suspended material was refluxed with methanol again twice, before combining all methanolic fractions and placing them in a rotary evaporator at low pressure, at a temperature of about $70^{\circ} \mathrm{C}$ to obtain the dry methanol fraction. The Lieberman Burchard's reagent assay indicated the presence of steroidal compounds in methanolic fraction, named the steroidal fraction in this work.

\section{Mosquito capture and breeding}

Mosquito capture was performed at various sites, mostly periurban, in Porto Velho, Rondônia, using the modified BGSentine ${ }^{\circledR}$ trap (Gama et al., 2013; Rodrigues et al., 2014). Then, adult females were allowed to feed on rabbit blood for 15 minutes (Siria et al., 2018) After 72 hours, oviposition was induced by wing removal. Larvae were kept under laboratory conditions (28ㅇ, $80 \%$ relative humidity and $12 \mathrm{~h}$ photoperiod) and fed with ground fish food (TetraMin Tropical Flakes) until the 3 o and 4 을 instar.

\section{Larvicidal bioassays}

The crude secretion and methanol $(\mathrm{MeOH})$ fractions of the venom were diluted in distillated water and evaluated as larvicides. A dose-response experiment was performed using five concentrations $(10,25,50,80,100 \mathrm{mg} / \mathrm{L})$, with four replicates and a control (distillated water), and 25 thirdfourth instar larvae in each condition. The experiment was repeated three times. Larval mortality was recorded after 48 hours. Moribund larvae that were debilitated and unable to reach the water surface when disturbed were considered dead (WHO, 2005).

\section{Statistical analysis}

Lethal concentrations ( $\mathrm{LC}_{50}$ and $\mathrm{LC}_{90}$ ) were estimated using the logit model. In this case, the model could be expressed as:

$$
\begin{aligned}
& y_{i} \sim \operatorname{bin}\left(p_{i}, n_{i}\right) \\
& \operatorname{logit}\left(p_{i}\right)=\beta_{0}+\beta_{1} * \text { concentration }
\end{aligned}
$$

So, a given LC could be defined as:

$$
L C=\left(\log (p /(1-p))-\beta_{0}\right) / \beta_{1}
$$

where $p$ is the desired probability (in our case 50 and 90).

This model was fitted using a Bayesian approach. In this case, the values and their credible intervals were obtained from a posterior. To compute the posterior, 50000 samples were drawn using the NUTS algorithm and two chains. The first 5000 samples were used to tune the algorithm. Then, we discarded the first 1000 samples and collected samples from the chains at every five cycles. Chain convergence was checked by visual inspection and Rhat. The model was fitted using python 3.7, using pymc3 to fit the Bayesian model. Figures were constructed using matplotlib, and the libraries pandas and numpy were used to perform data manipulation.

\section{RESULTS}

During the experiments, a total of 4800 larvae were used. In general, mortality was lower when we used secretions originating from $R$. marina. In this case, the overall mortality for the crude secretion was about $23 \%$ (standard deviation = 
$11 \%)$ and $19 \%(s d=3 \%)$ for the steroidal fraction (Figure 1 ). Secretions from $R$. guttatus led to a seven-fold higher overall mortality, irrespective of the fraction (crude secretion: $80 \%$, $\mathrm{sd}=2.5 \%$; steroidal: $92.2 \%, \mathrm{sd}=2.8 \%$ ) (Figure 2 ).

According to our model, an increase in the concentration of the secretions leads to an increase in the mortality. Thus, an increase of $1 \mathrm{mg} / \mathrm{L}$ of crude secretion from $R$. guttatus leads to a mean 1.04-fold increase in the odds of An. darlingi larvae mortality (Credible Interval: 1.03-1.04), whereas, in the steroidal fraction, this leads to a mean 1.06-fold increase in mortality (Crl: 1.05-1.07). A similar pattern was observed for R. marina; however, for fractions from this species, the mean increase in the odds was slightly lower, 1.02 (Crl: 1.021.03) for the crude fraction and 1.02 (Crl: 1.02-1.03) for the steroidal fraction.

Estimated lethal concentrations (LC) varied between the different anuran species and the fraction tested. Both the crude fraction and steroidal fraction LCs from secretions of $R$. marina were higher than those of the secretions of $R$. guttatus ( $\mathrm{LC}_{50}$ : 70.6 and 80.6\%; and $\mathrm{LC}_{90}$ : 59.4 and $73.2 \%$, respectively). Moreover, the $\mathrm{LC}_{50}$ and $\mathrm{LC}_{90}$ of the steroidal fraction were lower for R. guttatus, but similar for R. marina (Table 1 ).

\section{DISCUSSION}

Animal venoms share common characteristics and are typically characterized by complex combinations of proteins and peptides with great structural diversity. Important biochemical, physiological and pathological tools for the development of new drugs have arisen due to research on animal venoms (Calderon et al., 2009; Calderon et al., 2014). In this context, the toxins purified from the animal venom or skin secretion have a high potential for pharmacological and biochemical study, and may have biomolecules with great therapeutic and biotechnological applicability (Beleboni et al., 2004; King \& Hardy, 2012; Da Silva et al., 2014; Gimenez et al., 2014).

There is little data available regarding the toxic activity of anuran secretions on insects, and none are from true toads (Bufonidae). Williams et al. (1998) reported that a $1 \%$ skin secretion solution from Litoria caerulea (Anura: Hylidae) caused $57 \%$ mortality in larvae (topically applied) and $100 \%$ in adults (orally delivered) of flies (Lucilia cuprina and Calliphora stygia). Here, the tested concentration was 100 times higher than those used as larvicides in the present study (Figure 1 and 2). On the other hand, crude secretions from the skin of poison frogs (Anura: Dendrobatidae) kill larvae of An. darlingi and Aedes aegypti (Trindade et al., 2014) at much lower concentrations than those reported in the present work. Additionally, isolated compounds, such as pumiliotoxins seems to deter landing of Ae. aegypti on treated membranes (Weldon et al., 2006), supporting their role in the protection against predatory and ectoparasitic arthropods.
The Bufonidae family secrete compounds from four main classes: i) alkaloids; ii) biogenic amines; iii) steroids, such as bufodienolids or bufotoxins; and iv) proteins (Zelnik et al., 1964; Toledo \& Jared, 1995; Perry, 2000). Unlike the peptiderich skin secretions of Dendrobatidae frogs, Bufonidae frogs' skin secretions usually contain a high concentration of steroids such as bufodienolides (Chen \& Kovarikova, 1967; Filho et al., 2005; Conlon et al., 2009) and a low concentration of peptides (Rash et al., 2011), or even none at all (Medeiros et al., 2019).

Among different compounds in the crude secretion, bufodienolides extracted from $R$. marina and $R$. guttatus present several biological activities (Krenn \& Kropp, 1998; Cunha-Filho et al., 2010). Plant-derived bufodienolides, such as bryophyllin $A$ and $C$, showed insecticidal properties when ingested by third instar larvae of Bombyx mori (Supratman et al., 2000), but no data for the insecticidal effect of skin secretions from bufonids was found.

Despite both anuran species studied being true toads (Bufonidae), the crude and steroidal fractions of the skin secretion of $R$. guttatus caused higher mortality and resulted in lower LC values for An. darlingi larvae compared to those obtained from Rhinella marina (Figures 1, 2 and Table 1). However, Ferreira et al. (2013) reported that all of the fractions obtained from $R$. marina presented much higher cytotoxicity in different evaluated tumor cells compared to $R$. guttatus, arguing that this might have resulted from synergistic effects due to the higher number of bufodienolids present in the former species. Conversely, Oliveira et al. (2019) argued that $R$. guttatus extract had a higher inhibitory effect on splenic cells compared to the effect of $R$. marina extract.

Interestingly, Ferreira et al. (2013) reported that the secretion of $R$. marina contained four bufadienolides (telocinobufagin, marinobufagin, bufalin and resibufogenin) and the $R$. guttatus secretion contained only one (marinobufagin), while Kerfhoff et al. (2016) reported three bufadienolides (telocinobufagin, marinobufagin and bufalin) and Medeiros et al. (2019) reported only two bufadienolides (marinobufagin and desacetylcinobufagin) in the secretions from $R$. marina. However, the authors used different solvents during fractionation of crude secretions, for example: $\mathrm{CHCl}_{3} / \mathrm{MeOH}$ (8:2) (Ferreira et al., 2013); ethyl acetate $(100 \%)$, ethyl acetate/methanol $(80: 20 \mathrm{v} / \mathrm{v})$, ethyl acetate/methanol (50:50 v/v), ethyl acetate/methanol (20:80 $\mathrm{v} / \mathrm{v}$ ) and methanol (100\%) (Kerfhoff et al. 2016); and only methanol (100\%) (Medeiros et al., 2019).

Interestingly, Kerfhoff et al. (2016) argued that ethyl acetate $(100 \%)$ extraction resulted in greater amounts of bufadienolides. Therefore, the use of methanol, a more polar solvent, and a less diverse source of bufadienolides in the specimens used (Medeiros et al., 2019) in this work may have affected the synergistic effects of bufadienolides from R. marina, as argued by Ferreira et al. (2013). This is also

Table 1. Lethal concentrations $\left(\mathrm{LC}_{50}\right.$ and $\mathrm{LC}_{90}$ ) for the crude extract and methanolic fraction of Rhinella marina and Rhaebo guttatus secretions tested as larvicides on Anopheles darlingi

\begin{tabular}{lccr}
\hline Anura Species & Substance & $\mathrm{LC}_{50}(\mathrm{mg} / \mathrm{L})(\mathrm{Cl} 95 \%)$ & $\mathrm{LC}(\mathrm{mg} / \mathrm{L})(\mathrm{Cl} 95 \%)$ \\
\hline Rhinella marina & Crude extract & $127.54(113.20-143.5)$ & $224.4(191.5-260.4)$ \\
& Steroidal fraction & $133(117.7-149)$ & $220.2(188.2-254.8)$ \\
Rhaebo guttatus & Crude extract & $37.5(34.2-41)$ & $91.2(84.1-98.2)$ \\
& Steroidal fraction & $25.8(23.4-28.2)$ & $59.1(54.4-63.8)$ \\
\hline
\end{tabular}

$\mathrm{LC}_{50}$ and $\mathrm{LC}_{90}=$ concentrations necessary to kill $50 \%$ and $90 \%$, respectively, of the larvae during assays; $\mathrm{mg} / \mathrm{L}=\mathrm{milligram}$ per liter; $\mathrm{Cl}=$ upper and lower confidence intervals. 

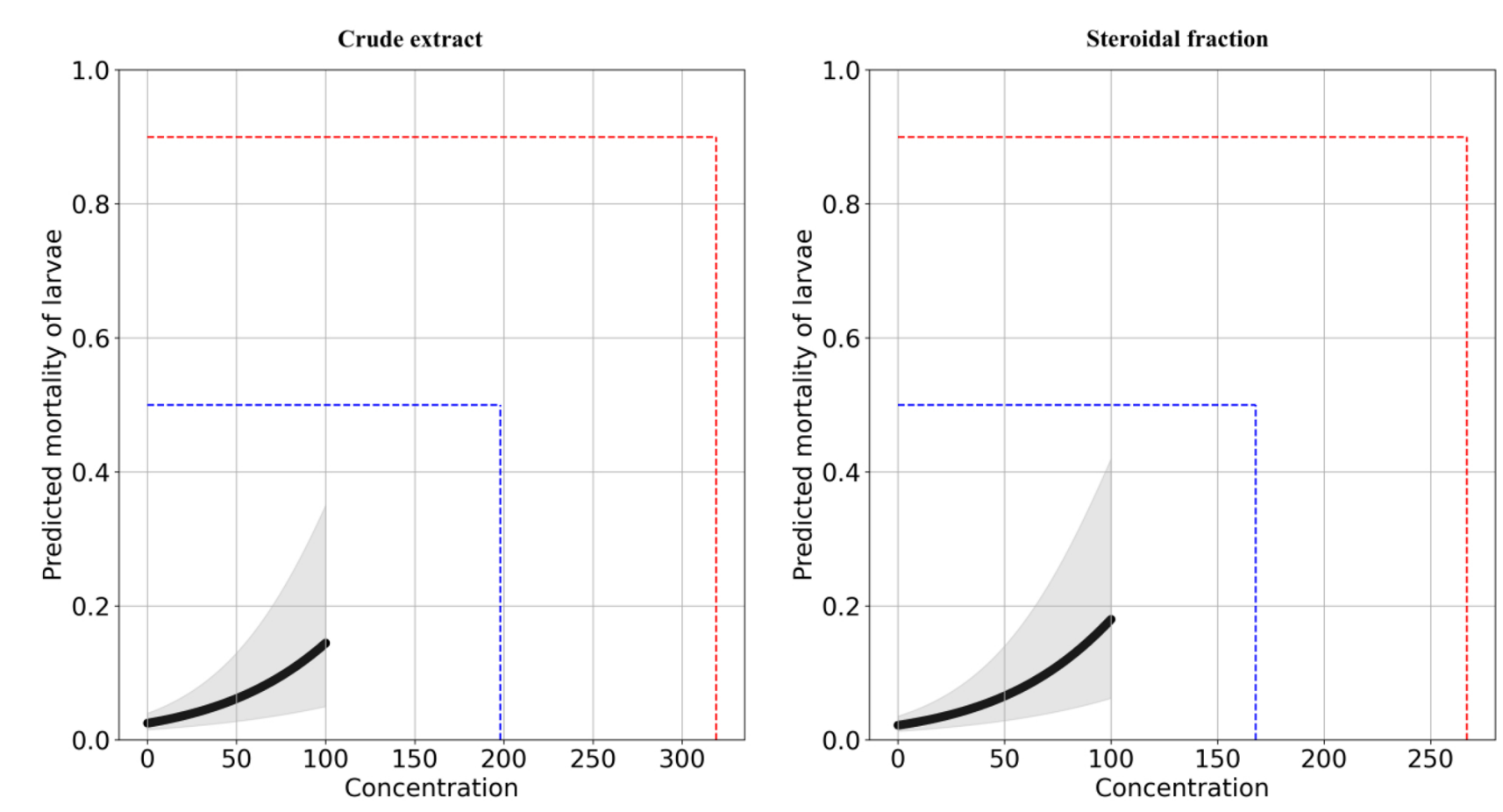

Figure 1. Larvicidal activity of Rhinella marina (Anura: Bufonidae) crude skin secretion and steroidal fraction against Anopheles darlingi at different concentrations and time points. Blue and red dotted lines indicate the estimated concentrations need to kill $50 \%$ and $90 \%$ of the larvae, respectively.
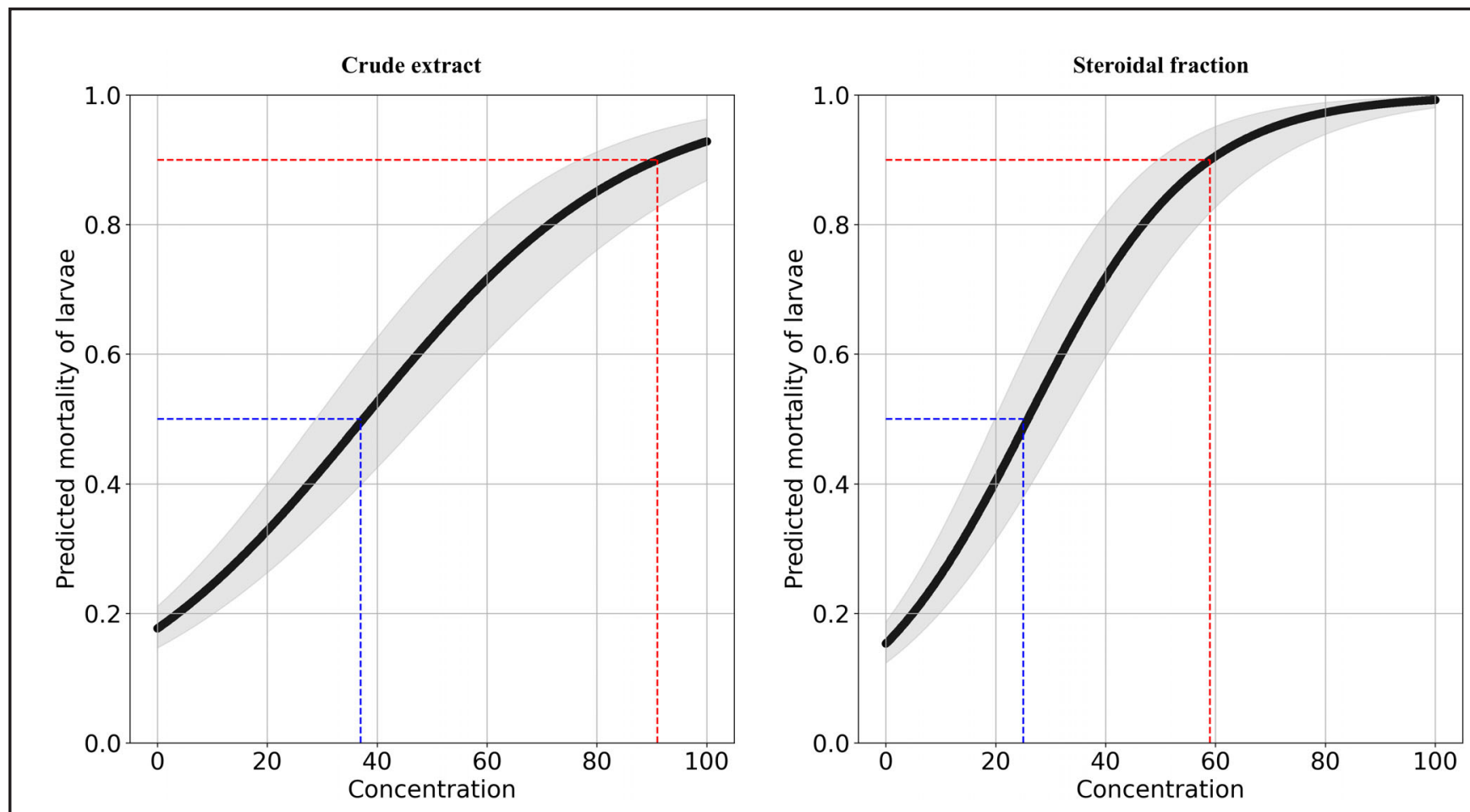

Figure 2. Larvicidal activity of Rhaebo guttatus (Anura: Bufonidae) crude skin secretion and steroidal fraction against Anopheles darlingi at different concentrations and time points. Blue and red dotted lines indicate the estimated concentrations need to kill $50 \%$ and $90 \%$ of the larvae, respectively. 
supported by the lack of an important bufadienolide usually present in the secretion of $R$. marina, telocinobufagin, which may have been responsible for the large reduction in parasitemia of the $P$. falciparum W2 strain caused by the $\mathrm{CHCl}_{3}$ / $\mathrm{MeOH}$ extract produced by Banfi et al. (2016).

Moreover, the effect of different fractions of the secretion of $R$. marina seems also to depend on the organism tested. For example, the crude extract had the lowest $I C_{50}$ against $P$. falciparum, while the methanolic fraction presented the lowest $\mathrm{IC}_{50}$ against Leishmania guyanensis (Medeiros et al., 2019). Additionally, an analysis of the skin secretion of $R$. marina showed that there was considerable variation $(0.13$ to $1.4 \mu \mathrm{mol} / \mathrm{mg}$ ) in concentrations of venom components during the toad ontogeny (Hayes et al., 2009), and that other factors such as diet and environmental factors may affect the composition and concentration of components (Gao et al., 2010).

\section{CONCLUSION}

The present work reports for the first time the larvicidal effects of the skin secretions of bufonid species occurring in the western Amazon region. Future studies with fractions from crude skin using other solvents and isolated compounds will improve our understanding of the insecticidal effects of these anuran species against mosquitoes.

\section{ACKNOWLEDGEMENTS}

We thank the Conselho de Gestão do Patrimônio Genético (CGEN/MMA) for the authorization number 010627/2011-1. The authors thank the Program for Technological Development in Tools for Health-PDTIS-FIOCRUZ for use of its facilities.The authors express their gratitude to Conselho Nacional de Desenvolvimento Científico e Tecnológico (CNPq) grants 575563/2008-7, 550854/2010-0 and 550934/2010-3, Coordenação de Aperfeiçoamento de Pessoal de Nível Superior (CAPES), Instituto Nacional de Ciência e Tecnologia de Epidemiologia da Amazônia Ocidental (INCT-EPiAmo), Instituto Nacional de Ciência e Tecnologia em Pesquisa Translacional em Saúde e Ambiente na Região Amazônica (INCT-INPeTAm), Instituto Nacional de Ciência e Tecnologia em Toxinas (INCT-Tox), Secretaria de Estado do Planejamento e Coordenação Geral (CNPq-SEPOG-RO), CICYT (CTQ2009-07758) and the Generalitat de Catalunya (2009SGR 1024) for the financial support.

\section{Conflict of interest}

The authors declare that they have no conflict of interests.

\section{REFERENCES}

Banfi, F.F., Guedes, K.S., Andrighetti, C.R., Aguiar, A.C., Debiasi, B.W. \& Noronha, J.C. (2016). Antiplasmodial and cytotoxic activities of toad venoms from Southern Amazon, Brazil. Korean Journal of Parasitology 54: 415-421. https://doi.org/ 10.3347/kjp.2016.54.4.415

Barra, D. \& Simmaco, M. (1995). Amphibian skin: A promising resource for antimicrobial peptides. Trends in Biotechnology 13: 205-209. https://doi.org/10.1016/S0167-7799(00) 88947-7

Beleboni, R.O., Pizzo, A.B., Fontana, A.C.K., Carolino, O.G., Coutinho-Netto, J. \& dos Santos, W.F. (2004). Spider and wasp neurotoxins: pharmacological and biochemical aspects. European Journal of Pharmacology 493: 1-17. https://doi.org/10.1016/j.ejphar.2004.03.049
Calderon, L.A., Silva, A.A., Ciancaglini, P. \& Stábeli, R.G. (2011). Antimicrobial peptides from Phyllomedusa frogs: from biomolecular diversity to potential nanotechnologic medical applications. Amino Acids 40: 29-49. https:// doi.org/10.1007/s00726-010-0622-3

Calderon, L.A., Silva-Jardim, I., Zuliani, J.P., Silva A.D.A.E., Ciancaglini, P., Silva, L.H.P.D. \& Stábeli, R.G. (2009). Amazonian biodiversity: a view of a drug development for Leishmaniasis and Malaria. Journal of the Brazilian Chemical Society 20: 1011-1023.

Calderon, L.A., Sobrinho, J.C., Zaqueo, K.D., de Moura, A.A., Grabner, A.N., Mazzi, M.V., Marcussi, S., Nomizo, A., Fernandes, C.F.C., Zuliani, J.P. et al. (2014). Antitumoral activity of snake venom proteins: New trends in cancer therapy. BioMed Research International 2014: 203639. https://doi.org/10.1155/2014/203639

Carlini, C.R. \& Grossi-De-Sá, M.F. (2002). Plant toxic proteins with insecticidal properties: A review on their potentialities as bioinsecticides. Toxicon 40: 1515-1539. https://doi.org/10.1016/S0041-0101(02)00240-4

Chen, K.K. \& Kovaøíková, A. (1967). Pharmacology and toxicology of toad venom. Journal of Pharmaceutical Sciences 56: 15351541. https://doi.org/10.1002/jps.2600561202

Conlon, J.M., Imawuro, S. \& King, J.D. (2009). Dermal cytolytic peptides and the system of innate immunity in anurans. Annals of the New York Academy of Sciences 1163: 75-82. https:/ /doi.org/10.1111/j.1749-6632.2008.03618.x

Cunha-Filho, G.A., Resck, I.S., Cavalcanti, B.C., Pessoa, C.O., Moraes, M.O., Ferreira, J.R.O., Rodrigues, F.A.R. \& Santos, M.L. (2010). Cytotoxic profile of natural and some modified bufadienolides from toad Rhinella schneideri parotoid gland secretion. Toxicon 56: 339-348. https://doi.org/ 10.1016/j.toxicon.2010.03.021

Da Silva, S.L., Rowan, E.G., Albericio, F., Stábeli, R.G., Calderon, L.A. \& Soares, A.M. (2014). Animal toxins and their advantages in biotechnology and pharmacology. BioMed Research International 2014: 951561. https://doi.org/10.1155/ 2014/951561

Ferreira, P.M.P., Lima, D.J.B., Debiasi, B.W., Soares, B.M., da Conceição Machado, K., da Costa Noronha, J., Rodrigues, D.J., Sinhorin, A.P., Pessoa, C. \& Vieira Jr, G.M. (2013). Antiproliferative activity of Rhinella marina and Rhaebo guttatus venom extracts from Southern Amazon. Toxicon 72: 43-51. https://doi.org/10.1016/j.toxicon.2013.06.009

Filho, G.A., Schwartz, C.A., Resck, I.S., Murta, M.M., Lemos, S.S., Castro, M.S., Kyaw, C., Pires Jr, O.R., Leite, J.R.S., Bloch Jr, C. et al. (2005). Antimicrobial activity of the bufadienolides marinobufagin and telocinobufagin isolated as major components from skin secretion of the toad Bufo rubescens. Toxicon 45: 777-782. https://doi.org/10.1016/j.toxicon.2005. 01.017

Frost, D.R. (2021). Amphibian species of the world: An online reference. Version 6.1. Electronic Database accessible at https://amphibiansoftheworld.amnh.org/index.php. American Museum of Natural History, New York, USA. https://doi.org/10.5531/db.vz.0001

Gama, R.A., Silva, I.M.D., Geier, M. \& Eiras, A.E. (2013). Development of the BG-Malaria trap as an alternative to human-landing catches for the capture of Anopheles darlingi. Memórias do Instituto Oswaldo Cruz 108: 763-771. https://doi.org/10.1590/0074-0276108062013013

Gao, H., Zehl, M., Leitner, A., Wu, X., Wang, Z. \& Kopp, B. (2010). Comparison of toad venoms from different Bufo species by HPLC and LC- DAD-MS/MS. Journal of Ethnopharmacology 131: 368-376. https://doi.org/10.1016/j.jep.2010.07.017 
Gimenez, G.S., Coutinho-Neto, A., Kayano, A.M., Simões-Silva, R., Trindade, F., Silva, A.A.E., Marcussi, S., Silva, S.L., Fernandes, C.F.C., Zuliani, J.P. et al. (2014). Biochemical and functional characterization of Parawixia bistriata spider venom with potential proteolytic and larvicidal activities. BioMed Research International 2014: 950538. https://doi.org/10.1155/2014/950538

Hayes, R.A., Crossland, M.R., Hagman, M., Capon, R.J. \& Shine, R. (2009). Ontogenetic variation in the chemical defenses of cane toads (Bufo marinus): Toxin profiles and effects on predators. Journal of Chemical Ecology 35: 391-399. https:/ /doi.org/10.1007/s10886-009-9608-6

Hemingway, J., Ranson, H., Magill, A., Kolaczinski, J., Fornadel, C., Gimnig, J., Coetzee, M., Simard, F., Roch, D.K., Hinzoumbe, C.K. et al. (2016). Averting a malaria disaster: will insecticide resistance derail malaria control? The Lancet 387: 1785-17888. https://doi.org/10.1016/S01406736(15)00417-1

Felipe Toledo, L., Trefoud Rodrigues, M., Jared, C., Kruth Verdade, V. \& Maria Antoniazzi, M. (2011). The Amazonian toad Rhaebo guttatus is able to voluntarily squirt poison from the paratoid macroglands. Amphibia- Reptilia 32: 546549. https://doi.org/10.1163/156853811X603724

Kerfhoff, J., Noronha, J.C., Bonfilio, R., Sinhorin, A.P., Rodrigues, D.J., Chaves, M.H. \& Vieira Jr, G.M. (2016). Quantification of bufadienolides in the poisons of Rhinella marina and Rhaebo guttatus by HPLC-UV. Toxicon 119: 311-338. https:// doi.org/10.1016/j.toxicon.2016.07.003

King, G.F. \& Hardy, M.C. (2012). Spider-venom peptides: Structure, pharmacology, and potential for control of insect pests. Annual Review of Entomology 58: 475-496. https:// doi.org/10.1146/annurev-ento-120811-153650

Krenn, L. \& Kropp, B. (1998). Bufadienolides from animal and plant sources. Phytochemistry 48: 1-29. https://doi.org/ 10.1016/S0031-9422(97)00426-3

Medeiros, D.S., Rego, T.B., Santos, A.D.A., Pontes, A.S., MoreiraDill, L.S., Matos, N.B., Zuliani, J.P., Stábeli, R.G., Teles, C.B.G., Soares, A.M. et al. (2019). Biochemical and biological profile of parotoid secretion of the Amazonian Rhinella marina (Anura: Bufonidae). BioMed Research International 2019: 2492315. https://doi.org/10.1155/2019/2492315

Ministério da Saúde (MS). (2020). Secretaria de Vigilância em Saúde. Boletim epidemiológico - Malária. Número especial. Brasília: MS, pp. 118.

Nicholson, G.M. (2007). Fighting the global pest problem: Preface to the special Toxicon issue on insecticidal toxins and their potential for insect pest control. Toxicon 49: 413422. https://doi.org/10.1016/j.toxicon.2006.11.028

Oliveira, A.F.D., Castoldi, L., Vieira Junior, G.M., Monção Filho, E.D.S., Chaves, M.H., Rodrigues, D.D.J. \& Sugui, M.M. (2019). Evaluation of antimutagenic and cytotoxic activity of skin secretion extract of Rhinella marina and Rhaebo guttatus (Anura, Bufonidae). Acta Amazonica 49: 145-151. https:// doi.org/10.1590/1809-4392201801751

Perry, P. (2000). Proteins of parotoid gland secretions from toads of genus Bufo. Contemporary Herpetology 2000: 1-3. https://doi.org/10.17161/ch.vi1.11962

Peterson, M.E. \& Roberts, B.K. (2013). Toads. In: Small Animal Toxicology, Peterson, M.E. \& Talcott, P.A. (editors) 3rd edition. St Louis: Elsevier, pp. 833-839.

Rash, L.D., Morales, R.A., Vink, S. \& Alewood, P.F. (2011). De novo sequencing of peptides from the paratoid secretion of the cane toad, Bufo marinus (Rhinella marina). Toxicon 57: 208-216. https://doi.org/10.1016/j.toxicon.2010.11.012

Rinaldi, A.C. (2002). Antimicrobial peptides from amphibian skin: An expanding scenario. Current Opinion of Chemical Biology 6: 799-804. https://doi.org/10.1016/S1367-5931(02) 00401-5
Rodrigues, M.S., Silva, I.M., Leal, L.B., Santos-Junior, C. \& Eiras, A.E. (2014). Development of a new mosquito retention system for the BG-Malaria trap to reduce the damage to mosquitoes. Journal of the American Mosquito Control Association 30: 184-190. https://doi.org/10.2987/14-6423R.1

Sinka, M.E., Bangs, M.J., Manguin, S., Rubio-Palis, Y., Chareonviriyaphap, T., Coetzee, M., Mbogo, C.M., Hemingway, J., Patil, A.P., Temperley, W.H. et al. (2012). A global map of dominant malaria vectors. Parasite \& Vectors 5: 69. https://doi.org/10.1186/1756-3305-5-69

Siria, D.J., Batista, E.P., Opiyo, M.A., Melo, E.F., Sumaye, R.D., Ngowo, H.S., Eiras, A.E. \& Okumo, F.O. (2018). Evaluation of a simple polytetrafluoroethylene (PTFE)-based membrane for blood-feeding of malaria and dengue fever vectors in the laboratory. Parasites \& Vectors 11: 236. https://doi.org/ 10.1186/s13071-018-2823-7

Stuart, S., Hoffmann, M., Chanson, J., Cox, N., Berridge, R., Ramani, P. \& Young, B. (2008). Threatened Amphibians of the World. 1st edition. Barcelona: Lynx Editions, pp. 758.

Supratman, U., Fujita, T., Akiyama, K. \& Hayashi, H. (2000). New insecticidal bufadienolide, Bryophyllin C, from Kalanchoe pinnata. Bioscience, Biotechnology, Biochemistry 64: 1310-1312. https://doi.org/10.1271/bbb.64.1310

Tadei, W.P. \& Dutary-Thatcher, B.D. (2000). Malaria vectors in the Brazilian Amazon: Anopheles of the subgenus Nyssorhynchus. Revista do Instituto de Medicina Tropical de São Paulo 42: 87-94. https://doi.org/10.1590/S003646652000000200005

Toledo, R.C. \& Jared, C. (1995). Cutaneous granular glands and amphibian venoms. Comparative Biochemistry and Physiology Part A: Physiology 111: 1-29. https://doi.org/ 10.1016/0300-9629(95)98515-।

Trindade, F.T.T., Soares, Â.A., de Moura, A.A., Rego, T.B., Soares, A.M., Stábeli, R.G., Calderon, L.A. \& Silva, A.A.E. (2014) Insecticidal activity of Leptodactylus knudseni and Phyllomedusa vaillantii crude skin secretions against the mosquitoes Anopheles darlingi and Aedes aegypti. Journal of Venomous Animals and Toxins including Tropical Diseases 20: 1-6. https://doi.org/10.1186/1678-9199-20-28

Weldon, P.J., Kramer, M., Gordon, S., Spande, T.F. \& Daly, J.W. (2006). A common pumiliotoxin from poison frogs exhibits enantioselective toxicity against mosquitoes. Proceedings of the National Academy of Sciences of the United States of Ameria 103: 17818-17821. https://doi.org/10.1073/pnas. 0608646103

Williams, C.R., Smith, B.P.C., Best, S.M. \& Tyler, M.J. (2006). Mosquito repellents in frog skin. Biology Letters 2: 242245. https://doi.org/10.1098/rsbl.2006.0448

Williams, C.R., Wallman, J.F. \& Tyler, M.J. (1998). Toxicity of green tree frog (Litoria caerulea) skin secretion to the blowflies Calliphora stygia (Fabricius) and Lucilia cuprina (Wiedemann) (Diptera: Calliphoridae). Australian Journal of Entomology 37: 85-89. https://doi.org/10.1111/j.14406055.1998.tb01551.x

World Health Organization (WHO) (2005). Guidelines for laboratory and field testing of mosquito larvicides. WHO. Geneva, pp. 39.

World Health Organization (WHO) (2020). World malaria report 2020: 20 years of global progress and challenges. WHO. Geneva, pp. 299.

Zelnik, R., Ziti, L.M. \& Guimarães, C.V. (1964). A chromatography study of the bufadienolides isolated from the venom of the parotoid glands of Bufo paracnemis Lutz, 1925. Journal of Chromatography A 15: 9-14. https://doi.org/10.1016/S00219673(01)82734-5 